\title{
Increased High Mobility Group Protein A2/SMAD3 Relates to Ovarian Cancer Progression
}

Kimberly P. Dobrinski ${ }^{1}$, Christina D. Drenberg ${ }^{2}$, Jeffrey L. Edelman ${ }^{1}$, Stephanie T. Buttermore ${ }^{1}$, Mai Mohamed ${ }^{1}$, Vladimir N. Uversky ${ }^{3}$, Mitchel S. Hoffman ${ }^{4}$, Santo V. Nicosia ${ }^{1,5}$ and Patricia A. Kruk ${ }^{\star 1,4,5}$

${ }^{1}$ Department of Pathology \& Cell Biology, University of South Florida, Tampa, Florida, USA

${ }^{2}$ Department of Pharmaceutical Sciences, St. Jude Children's Research Hospital, Memphis, Tennessee, USA

${ }^{3}$ Department of Molecular Medicine, University of South Florida, Tampa, Florida, USA

${ }^{4}$ Department of Obstetrics and Gynecology, University of South Florida, Tampa, Florida, USA

${ }^{5} \mathrm{H}$. Lee Moffitt Cancer Center, Tampa, Florida, USA

${ }^{*}$ Corresponding author: Patricia A. Kruk, PhD, Department of Pathology \& Cell Biology, University of South Florida 12901 Bruce B. Downs Blvd, Tampa, FL 33612, Tel: (813)-974-0548, E-mail: pkruk@health.usf.edu

Citation: Kimberly P. Dobrinski, Christina D. Drenberg, Jeffrey L. Edelman, Stephanie T. Buttermore, Mai Mohamed, et al. (2015) Increased High Mobility Group Protein A2/SMAD3 Relates to Ovarian Cancer Progression. J Gynecol Res 1(1): 104. doi: 10.15744/2454-3284.1.104

Received Date: February 17, 2015 Accepted Date: April 24, 2015 Published Date: April 27, 2015

\begin{abstract}
Introduction: The high mortality associated with ovarian cancer is generally related to the development of drug-resistant disease. HMGA2 protein, a member of the high-mobility group AT-hook (HMGA) family of non-histone chromatin binding factors, is overexpressed in high-grade serous ovarian and tubal carcinomas, though little is known about its contribution to disease progression and drug resistance. We sought to assess whether compositional changes in HMGA2 production were associated with ovarian cancer progression.

Methods: We performed computational characterization of HMGA2 protein disorder, aggregation propensity and interactability. Cultures of established human ovarian cancer cell lines and immortalized ovarian surface epithelial cells were subjected to MTS growth assays, western immunoblotting and immunoprecipitation analyses for HMGA2, SMAD3 and SNAIL1 expression. Lastly, urine samples from healthy controls, women with benign gynecologic disease and women with ovarian cancer were analyzed by western immunoblotting for HMGA2 and SMAD3 levels.

Results: HMGA2 is a highly disordered protein with the potential to bind multiple protein partners, including SMAD3. Characteristics of HMGA2 binding partners suggested possible recruitment of HMGA2 for extracellular transport. We verified overexpression and secretion of HMGA2 and SMAD3 in cultures of ovarian cancer cells, especially with emergence of drug resistance. In agreement with computational analyses, we demonstrated that HMGA2 and SMAD3 protein can associate into a larger protein complex in ovarian cancer cells. Lastly, elevated levels of HMGA2 and SMAD3 were found in urine samples from ovarian cancer patients.

Conclusion: Our data suggest that the presence of and/or changes in the levels of a unique HMGA2/SMAD3 protein complex might serve as a useful biomarker and/or therapeutic target for ovarian cancer.

Keywords: Ovarian cancer; HMGA2; Drug resistance

Abbreviations: BMI: Body mass index; CB: Carboplatin; CM: Conditioned medium; ECL: Enhanced chemiluminescence; EMT: Epithelial-mesenchymal transition; FIGO: Federation of Gynecology and Obstetrics; HIOSE: SV-40 Large T antigen transfected ovarian surface epithelial cells; HMGA: High-mobility group AT-hook; HMGA2: High-mobility group protein A2; IP: Iimmunoprecipitation; kDa: Kilodaltons; OC: Ovarian cancer; PBS: Phosphate buffered saline; RIPA: Radioimmunoprecipitation assay; SDS-PAGE: Sodium dodecyl sulfate polyacrylamide gel electrophoresis; S.E.: Standard error; TGF- $\beta$ : Transforming growth factor- $\beta$; WB: Western immunoblotting
\end{abstract}

\section{Introduction}

Ovarian cancer (OC) is the fifth most common cancer among American women and it has the highest mortality among all gynecological cancers [1]. Over 21,000 new cases and over 14,000 deaths are estimated to occur in 2015, respectively. The diagnosis: death ratio of 1:4 and an overall 5-year-survival less than $40 \%$ are among the highest for female malignancies in the United States, mostly due to late stage discovery and emergence of drug-resistant disease. Surgical tumor reduction followed by platinum based chemotherapy remains the mainstay of therapy in the management of advanced epithelial OC [2]. While the response to primary chemotherapy can be as high as $76 \%$, the response rate is dramatically reduced after relapse of disease [2,3]. Platinum resistance, defined as disease recurrence less than six months from completion of therapy, is an important prognostic predictor [3]. Therefore, it is imperative to understand and abrogate drug resistant disease. 
High Mobility Group protein A2 (HMGA2) is a member of the non-histone chromosomal high mobility group protein family. HMGA2 contains 3 DNA-binding domains, or A/T hooks, and acts as a transcriptional regulator [4]. HMGA2 is overexpressed in a number of cancers [5-9], including OC [10] and especially in highly aggressive Type II high-grade papillary serous carcinomas of the fallopian tube and ovary [11-13]. These OCs contain genetic instability distinguished by a p53 mutation signature [14]. Overexpression of HMGA2 is associated with increased tumor growth [15], metastasis [16], poor clinical outcome [17,18] and emergence of drug-resistant disease [19]. HMGA2 appears to mediate tumor progression by promoting epithelial-mesenchymal transition (EMT) [20]. Additionally, HMGA2 may confer drug resistance through increased DNA base excision repair due to inherent DNA lyase activity [21]. Since silencing HMGA2 results in reduced tumor growth [22-24], HMGA2 may represent an important therapeutic target. In order to better understand the mechanisms that may regulate OC development, we sought to determine whether compositional changes in HMGA2 are related to OC progression and emergence of drug resistance.

\section{Materials and Methods}

\section{Computational analyses}

The distributions of intrinsic disorder propensity within the amino acid sequences of human HMGA2 (109 amino acids, UniProt ID: P52926) and SMAD3 (425 residues, UniProt ID: P84022) were determined using PONDR ${ }^{\circledR}$ VLXT $_{\text {[25], PONDR }}{ }^{\oplus}$ VL3 [26], PONDR $^{\odot}$ VSL2B [27] and PONDR-FIT [28] algorithms. Potential amyloidogenic regions, regions responsible for amyloid formation and protein aggregation, were identified in HMGA2 protein using the FoldAmyloid software program [29]. Intrinsic regions of protein disorder within the human HMGA2 protein were predicted using the ANCHOR algorithm and the IUPred disorder prediction tool [30,31]. Potential protein binding partners of HMGA2 and SMAD3 were predicted using the String 9.1 platform [32]. Potential post-translational glycosylation modification sites within the human SMAD3 sequence were identified by the HMMpTM algorithm [33].

\section{Tissue culture}

The following cells were used: SV-40-Large T-Antigen transfected human ovarian surface epithelium (HIOSE) cell lines HIOSE 1816-575, 117, 118, MCC3; colon cancer cell line SW626 and; OC cell lines A2780s, A2780cp, OV2008, C13, CAOV3, OVCAR5, TOV12D, OV-90. All cells were cultured in Medium 199:MCDB 105 media (1:1) (Sigma, St. Louis, MO) with 10\% fetal bovine serum and gentamicin and incubated at $37^{\circ} \mathrm{C}$ with $5 \% \mathrm{CO}_{2}: 95 \%$ air as described previously [34].

\section{Urine samples}

With prior University of South Florida Institutional Review Board committee approval, anonymized urine samples from women with benign ovarian disorders $(\mathrm{N}=3)$, patients with epithelial OC $(\mathrm{N}=13)$ and healthy controls $(\mathrm{N}=5)$ were released for this pilot research project. Where possible, anonymized matched $\mathrm{H} \& \mathrm{E}$ sections from paraffin blocks were reviewed to confirm the histologic diagnosis according to International Federation of Gynecology and Obstetrics (FIGO) scores. Urine samples were kept on ice following collection, centrifuged at $3000 \times \mathrm{g}$, aliquoted and stored at $-20{ }^{\circ} \mathrm{C}$. For initial comparisons of urinary levels of $\mathrm{HMGA} 2$ by western immunblotting (WB) between healthy controls $(\mathrm{N}=5)$ and two sets of $\mathrm{OC}(\mathrm{N}=5$ each), urine samples were pooled to ensure sufficient amounts of protein for analyses. For comparisons of urinary levels of HMGA2 and SMAD3 from individual patients with benign gynecologic disease $(\mathrm{N}=3)$ and OC $(\mathrm{N}=3)$, equivalent volumes of urine were concentrated using Amicon Centriplus centrifugal filters (Millipore, Billerica, MA) to ensure sufficient amounts of protein for WB analyses.

\section{Cell Growth}

Cell growth was measured by the CellTiter $96^{\circledR} \mathrm{AQ}_{\text {ueous }}$ One Solution Cell Proliferation MTS (Promega, Madison, WI) colorimetric assay. The assay was performed in 96 well microtiter plates according to manufacturers' instructions. Two thousand cells were plated on 96 well microtiter plates and selected for carboplatin (CB) resistance at intervals following bi-weekly treatments of $4 \mathrm{x}$ $5 \mu \mathrm{M} \mathrm{CB}$, followed by $4 \times 10 \mu \mathrm{M} \mathrm{CB}$. Absorbance at $490 \mathrm{~nm}$ was measured at $0,24,48$, and 72 hours following treatment using an $\mathrm{EL}_{\mathrm{x}} 800$ microplate reader (Bio-Tek Instruments, Winooski, VT) and the results expressed as the mean absorbance \pm standard error (S.E.).

\section{Western Immunoblotting}

Cells were washed in phosphate buffered saline (PBS), trypsinized, pelleted, and washed again in cold PBS. Cells were lysed for 30 minutes on ice in modified CHAPS buffer, and the lysate was centrifuged at $115,000 \mathrm{x} \mathrm{g}$, at $4{ }^{\circ} \mathrm{C}$ for $1 \mathrm{~h}$. Thirty $\mu \mathrm{g}$ of protein were separated via $10 \%$ sodium dodecyl sulfate polyacrylamide gel electrophoresis (SDS-PAGE). Proteins were transferred to polyvinylidene fluoride membranes, dried, and blocked in 5\% milk in Tween 20-Tris buffered saline. Blots were incubated in their respective primary antibodies overnight, followed by incubation with a horseradish peroxidase-conjugated secondary antibody and developed via enhanced chemiluminescence substrate (ECL) (Pierce/ Fisher, Pittsburgh, PA). Antibodies: HMGA2 (1:1000) Cat. \# H00008091-M02 from Abnova (Taiwan), SMAD3 (1:1000) Cat. \# ab40854 from Abcam (Cambridge, MA), SNAIL1 (1:2000) Cat. \# 14-9859 from eBioscience (San Diego, CA), Actin clone AC-40 (1:10,000) Cat. \# 4700 Sigma (St. Louis, MO). WB quantification was performed using ImageJ software normalizing band strength to the respective actin band. 


\section{Immunoprecipitation}

For immunoprecipitation (IP), cells were washed with PBS and incubated on ice with radioimmunoprecipitation assay (RIPA) lysis buffer containing protease inhibitors. After 15 minutes, the cells were removed by scraping, the lysates were incubated for 60 minutes on ice and then the lysates were centrifuged at $10,000 \mathrm{xg}$ for 10 minutes at $4{ }^{\circ} \mathrm{C}$. Two $\mu \mathrm{g}$ of primary antibody were incubated with $1 \mathrm{mg}$ of whole cell lysate for 2 hours at $4^{\circ} \mathrm{C}$. Protein $\mathrm{A} / \mathrm{G}$ agarose suspension was added to lysate/antibody mixture followed by incubation at $4{ }^{\circ} \mathrm{C}$ on a rocker overnight. The suspension was collected by centrifugation at $500 \mathrm{xg}$ for $2 \mathrm{minutes}$ at 4 ${ }^{\circ} \mathrm{C}$. The pellet was washed with RIPA buffer containing protease inhibitors followed by WB analysis.

\section{Statistics}

For MTS assays, student's t-tests were performed to assess statistical difference between means of triplicates \pm S.E. from three separate experiments.

\section{Results and Discussion}

\section{HMGA2 is a highly disordered protein capable of binding many proteins}

Computational analyses of HMGA2 using four disorder predictors of the PONDR family indicated that HMGA2 is a highly disordered protein throughout its whole 109 amino acid length (Figure 1A). Therefore, the HMGA2 protein does not have a stable secondary and/or tertiary structure, existing instead as a highly dynamic ensemble of multiple interconverting forms. Since intrinsically disordered proteins are associated with low aggregability, the FoldAmyloid program was used to assess the aggregation propensity of HMGA2. As indicated in Figure 1B, failure to achieve threshold status confirmed that HMGA2 has a low aggregation propensity consistent with properties of a disordered protein.

A

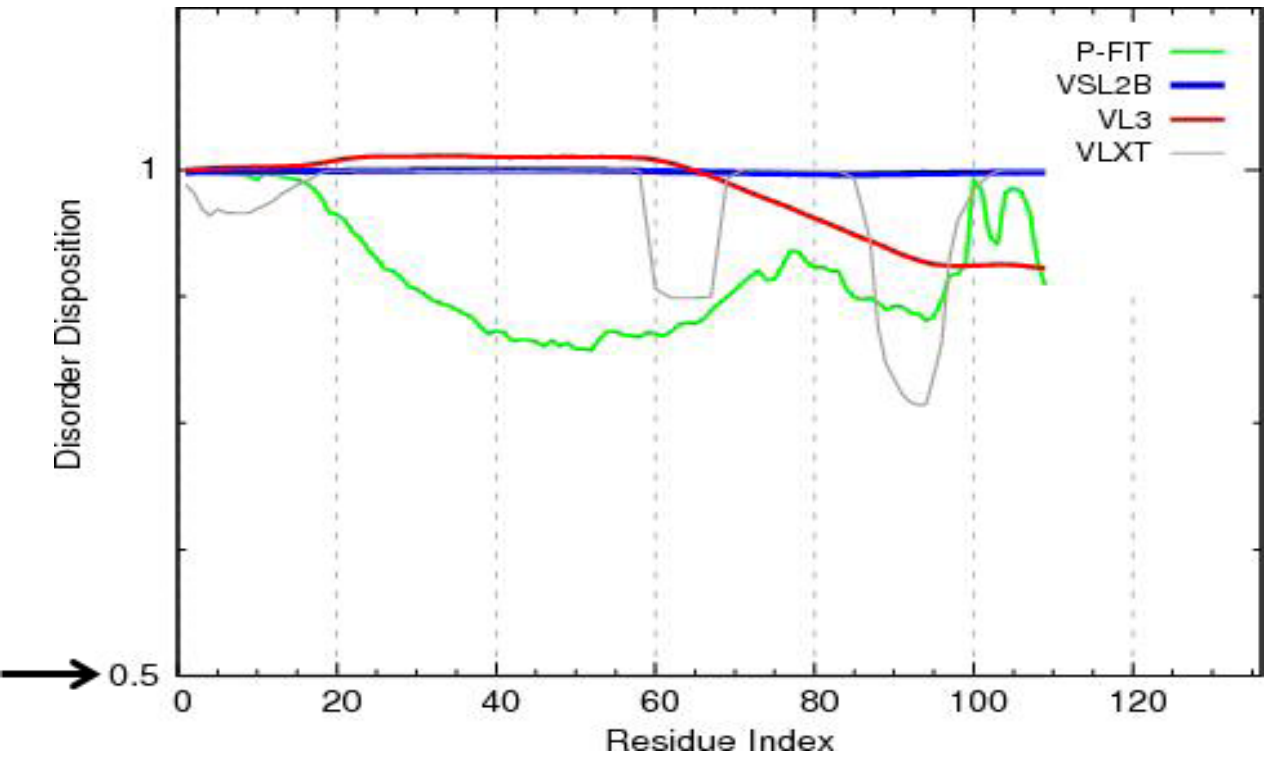

B

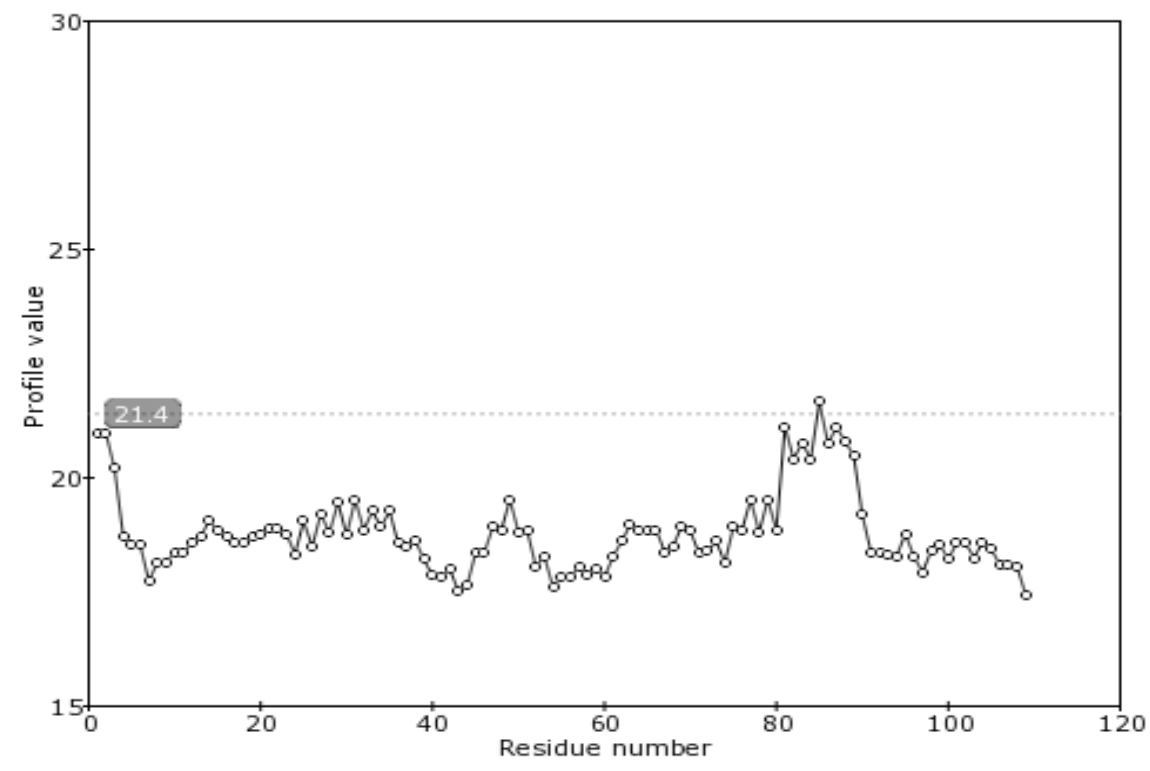


The intrinsic plasticity of such a highly disordered protein also implies that HMGA2, as typical of intrinsically disordered proteins, can interact with a multitude of protein binding partners [35]. This assumption was supported by ANCHOR-based analysis which identified three discrete regions (residues 1-33, 52-73 and 78-93) as potential protein binding sites within HMGA2 (Figure 1C). Interestingly, these sites correspond to the three HMGA2 AT hooks located at amino acids 25-33, 45-51 and 73-83 [36], respectively. Lastly, results of the String-based analysis show that HMGA2 can interact with numerous protein partners, including SMAD 3 and SMAD 4 proteins (Figure 1D).

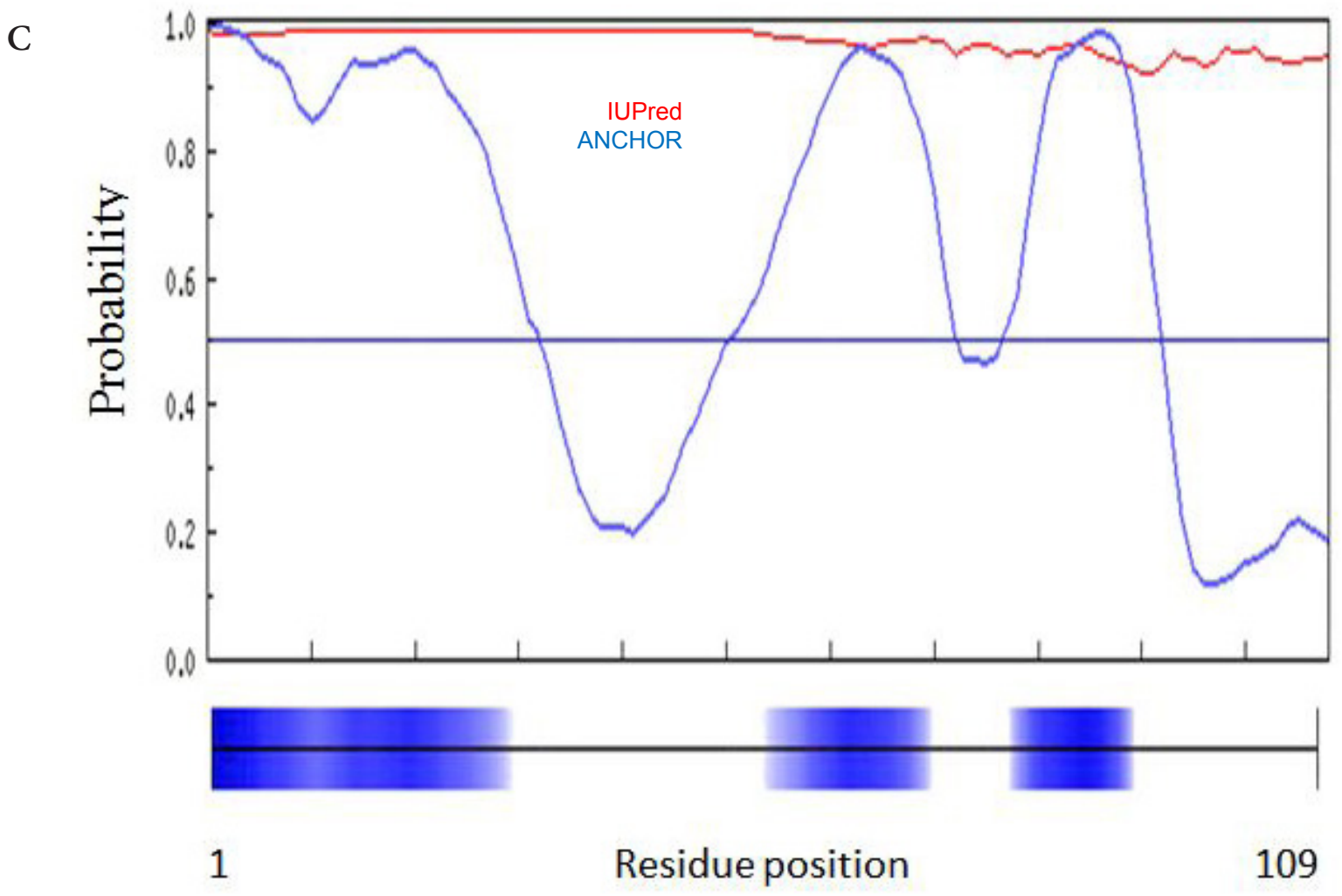

D

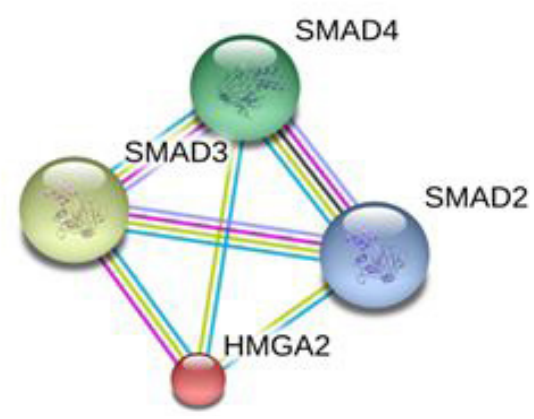

Figure 1: HMGA2 is an intrinsically disordered protein. A) The disorder propensity of human HMGA2 (UNiProt ID:P52926) was evaluated by the members of the PONDR family of disorder predictors. Scores above 0.5 (arrow) correspond to disordered residues/regions. B) Failure to surpass threshold status (dotted line) with FoldAmyloid program analysis indicated that HMGA2 is essentially non-amyloidogenic and has a low propensity to self-aggregate. C) The ANCHOR prediction tool was employed to identify potential protein-binding sites in HMGA2. Three regions encompassing amino acid residues 1-33, 52-73 and 78-93 were identified as potential protein binding sites within HMGA2. D) Analysis of the interactivity of human HMGA2 by String produces the network of predicted associations for a particular group of proteins. The network nodes are proteins, whereas the edges represent the predicted or known functional associations. An edge may be drawn with up to 7 differently colored lines that represent the existence of the seven types of evidence used in predicting the associations. A red line indicates the presence of fusion evidence; a green line - neighborhood evidence; a blue line - co-occurrence evidence; a purple line - experimental evidence; a yellow line - text mining evidence; a light blue line - database evidence; a black line - co-expression evidence [32].

SMAD3 belongs to a protein family involved in receptor-mediated transforming growth factor- $\beta$ (TGF- $\beta$ ) signal transduction [37]. Activation by TGF- $\beta$ results in SMAD2 and SMAD3 phosphorylation with subsequent trimerization between SMAD2, SMAD3 and SMAD4. Additionally, HMGA2 has been shown to physically interact with SMAD3, and to a lesser extent with SMAD2 and SMAD4, in human embryonic kidney cells [38]. The SMAD complex then translocates into the nucleus and binds to DNA to drive transcription for genes involved in EMT [39]. SMAD3 is also a moderately disordered protein with predicted disordered regions 
encompassing approximately $20 \%$ of its sequence (Figure 2A). Interestingly, the disordered regions of SMAD3 encompass portions of its amino MH1 domain (amino acid residues 31-131), which, with its carboxy MH2 (amino acid residues 226-403) domains [40] are responsible for binding HMGA2 [38]. Analyses of potential post-translational modifications in SMAD3 by HMMpTM software program predicted glycosylation of SMAD3 at amino acid residues 339, 344, 345, 357, 388 and 418 associated with a SMAD3 transmembrane domain at residues 296 - 314 (Figure 2B). Therefore, HMGA2 could be recruited to cellular membranes via its interaction with SMAD3. Finally, Figure $2 \mathrm{C}$ shows that similar to the HMGA2 protein, SMAD3 is predicted to have a large number of potential binding partners, including HMGA2, and, therefore, also serves as an important hub protein. Consequently, while TGF- $\beta$-mediated signaling activates the formation and nuclear translocation of an HMGA2/SMAD complex to drive EMT, computational analyses of an HMGA2/SMAD3 complex suggests that this complex could be recruited to the cell membrane for possible extracellular transport.

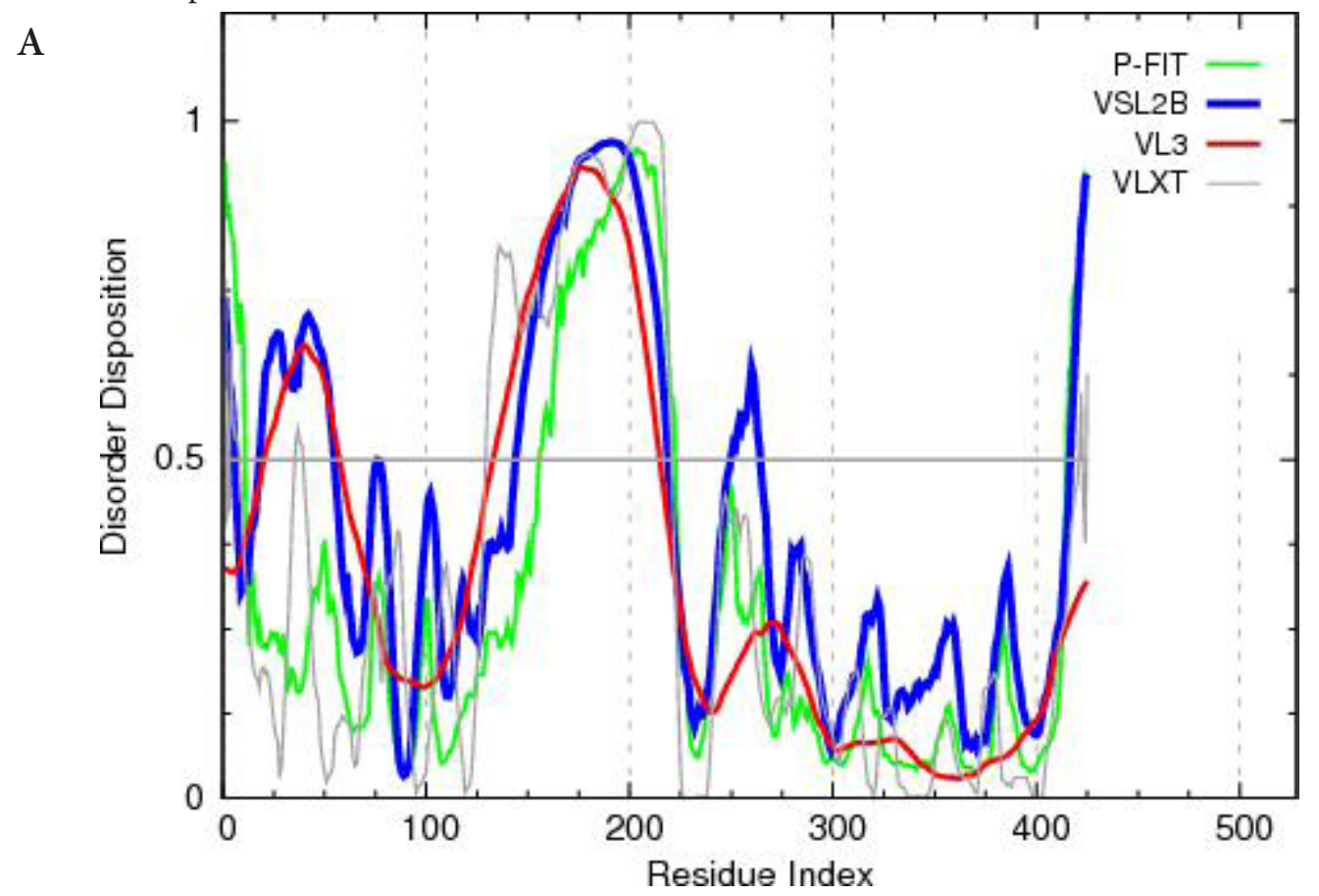

B

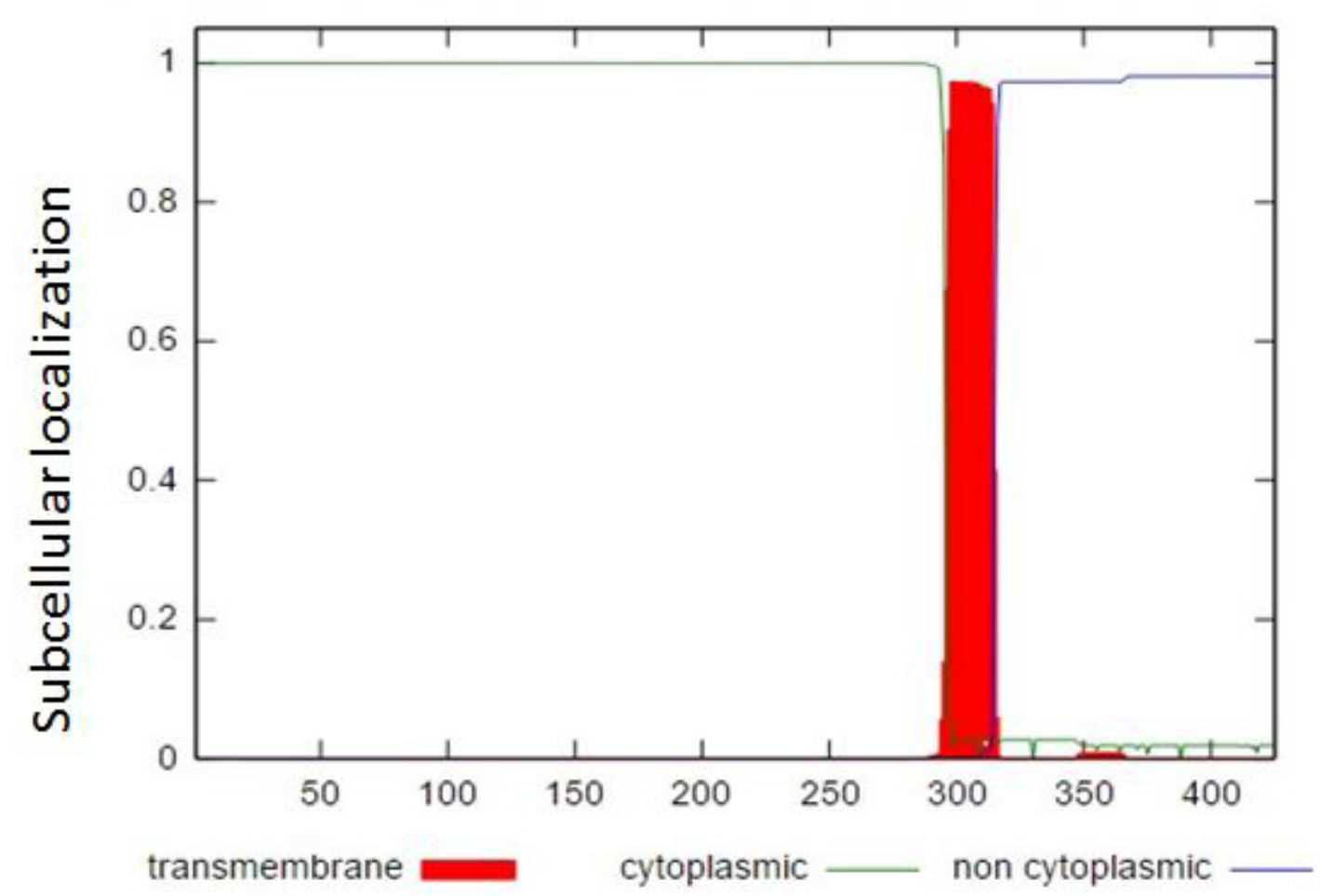




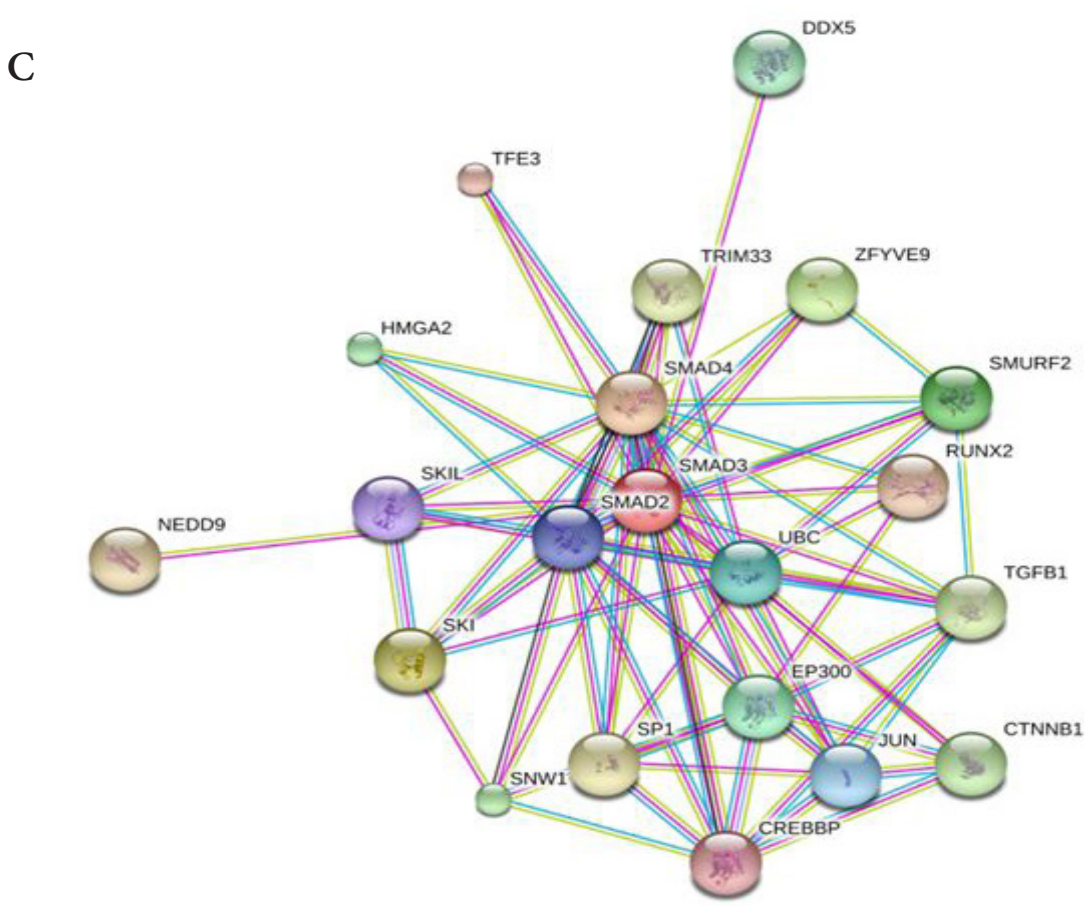

Figure 2: SMAD3 is a predicted HMGA2 binding partner. A) The disorder propensity of human SMAD3 (425 residues, UniProt ID: P84022) was evaluated by the members of the PONDR family of disorder predictors. Scores above 0.5 correspond to disordered residues/regions. B) The HMMpTM software program was used to predict glycosylation sites within SMAD3. Amino acid residues $339,344,345,357,388$ and 418 were predicted as potential glycosylation sites and are associated with a SMAD3 transmembrane domain spanning amino acid residues 296 - 314 . C) Analysis of the interactivity of human SMAD3 (UniProt ID: P84022) by String analysis as in Figure 1D.

\section{Levels of HMGA2 increase with ovarian transformation and cancer progression in culture}

Given reports of HMGA2 overexpression in OC, an HMGA2/SMAD3 complex could be associated with OC progression. To expand our understanding of the role of HMGA2 in OC, we surveyed HMGA2 protein levels by WB among HIOSE cells and cancer cell lines (Figure 3). Normal cells (HIOSE 1816-575, 117, 118 and MCC3) failed to show any detectable levels of HMGA2 at the expected $18 \mathrm{kDa}$ HMGA2 size consistent with published reports that HMGA2 is not expressed in normal somatic cells [41]. The colon cancer cell line, SW626, also demonstrated undetectable levels of HMGA2 which may reflect degree of tumor progression. A recent report by Rizzi et al. [42] showed that HMGA2 negative colon cancers surrounded by HMGA2 positive stromal fibroblasts were associated with improved clinical outcome compared to HMGA2 positive colon cancers in an environment of HMGA2 negative stromal fibroblasts. A possible role of genetic and epigenetic events in cancer associated stroma has been similarly described for prostate cancer development [43] and underscores the role of stroma for tumor progression. High expression of HMGA2 was noted in 5 out of 7 OC cell lines, consistent with the literature reporting elevated levels of HMGA2 in OC [10-13]. Interestingly, among pairs of drug-sensitive parental OC cell lines (A2870s, OV2008) and their respective drug-resistant daughter cell lines (A2780cp, C13), we found that levels of HMGA2 were increased up to 850x in drug-resistant daughter cell lines (Figure $3 \mathrm{~A})$, thereby further supporting overexpression of HMGA2 with OC progression.

\section{HMGA2 forms a complex with SMAD3 in OC cells}

The reported molecular weights for HMGA2 and SMAD3 are 18 and $52 \mathrm{kDa}$, respectively. While disordered proteins typically display aberrant electrophoretic migration as larger molecular weight proteins due to their high ratio of charged to hydrophobic residues which subsequently interferes with SDS binding [44], we noted additional higher molecular weight HMGA2 protein bands at 100 and $200 \mathrm{kDa}$ on WB, generally limited to OC cell lines (Figure 3B). Additional WB analyses from OV2008 and C13 cell lysates not only confirmed increased levels of HMGA2 protein in drug-resistant cells (Figure 4A, B), but also confirmed elevated levels of SMAD3 present in western immunblots at 100 and $200 \mathrm{kDa}$ (Figure 4A, B) suggesting that HMGA2 and SMAD3 might be present in a complex in OC cell cultures. Levels of high molecular weight HMGA2 and SMAD3 were $98 \%$ and $30 \%$ greater, respectively, in the drug-resistant C13 cells compared to their parental drug-sensitive OV2008 OC cells. To differentiate between non-specific binding and the presence of larger molecular weight protein species associated with HGMGA2/SMAD3 protein complexes, immunoprecipitation (IP) was performed followed by WB on OV2008 and C13 cell lysates. We found that IP for HMGA2 co-localized with SMAD3 and IP for SMAD3 co-localized with HMGA2 at molecular weights of 100 and 200 $\mathrm{kDa}$ (Figure 4C) confirming for the first time the presence of HMGA2/SMAD3 as components of a complex in cultured OC cells. Consequently, our data are in agreement with others [38] and underscore the possible contribution of an HMGA2/SMAD3 complex for tumor progression by enhanced EMT. 
A

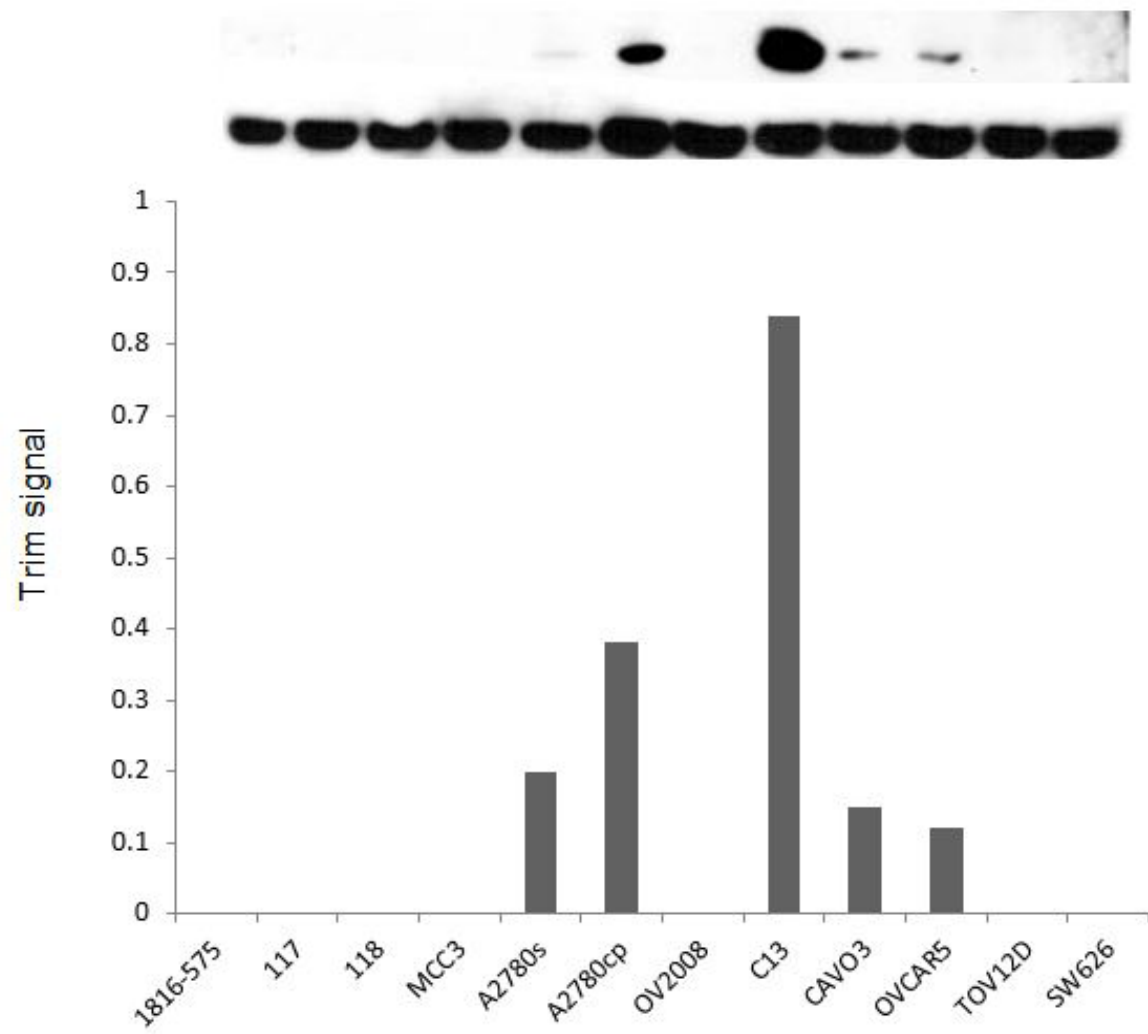

B

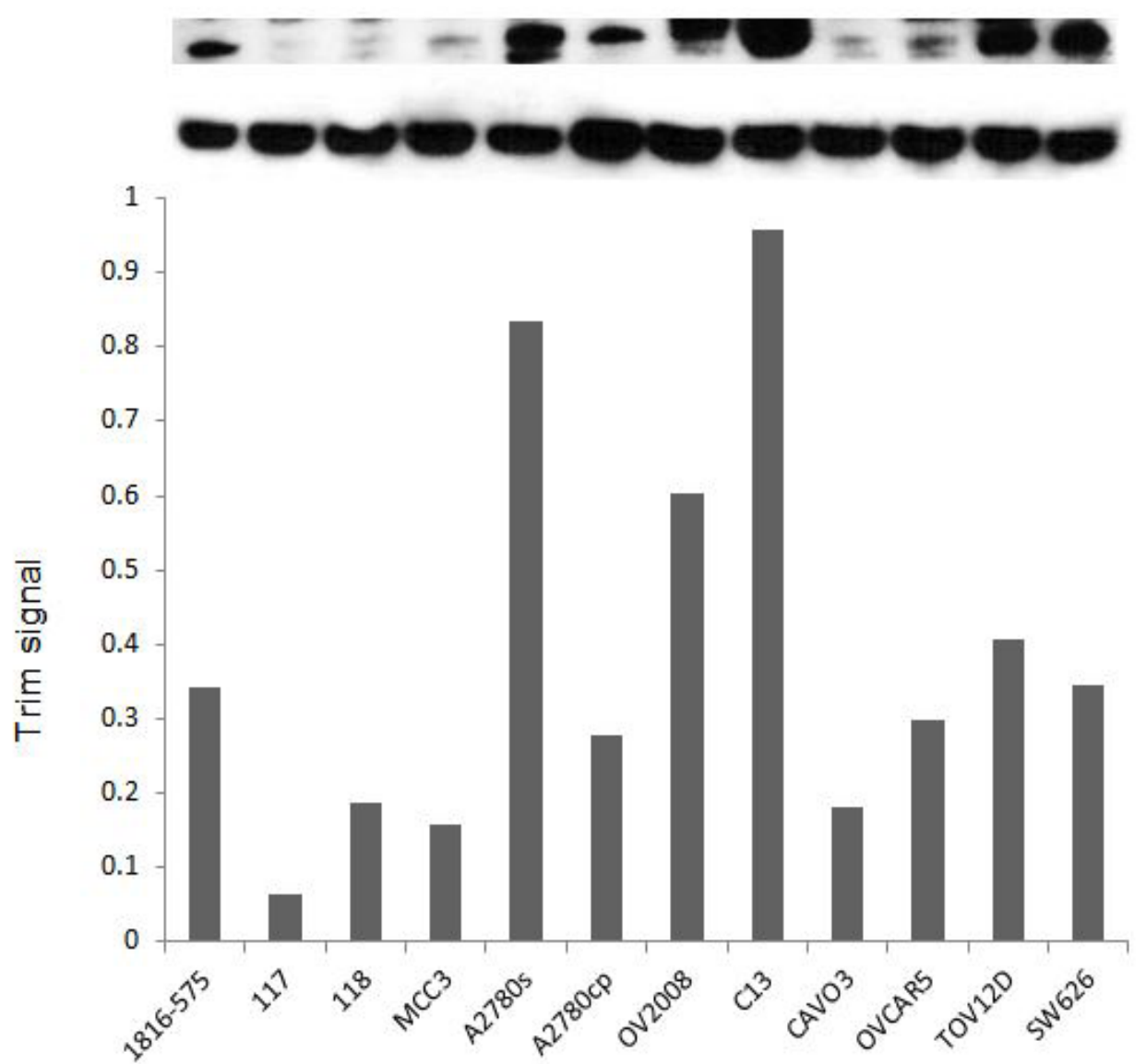

Figure 3: Endogenous protein levels of HMGA2 increase with OC progression. Endogenous levels of cellular $18 \mathrm{kDA}$ (A) and $100 \mathrm{kDA}$ (B) HMGA2 were assayed by western immunoblotting among HIOSE (1816-575, 117, 118, MCC3), colon cancer (SW626) and ovarian cancer (A2780s, A2780cp, OV2008, C13, CAOV3, OVCAR5, TOV12D) cell lines. Graphs represent average densitometric values of HMGA2 normalized to actin (upper panel in each figure, representative western immunoblot). 
A

OV2008 C13
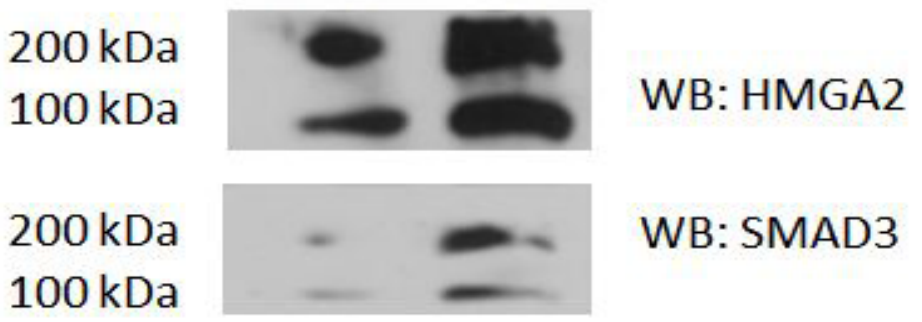

$42 \mathrm{kDa} \longrightarrow$ WB: Actin

B

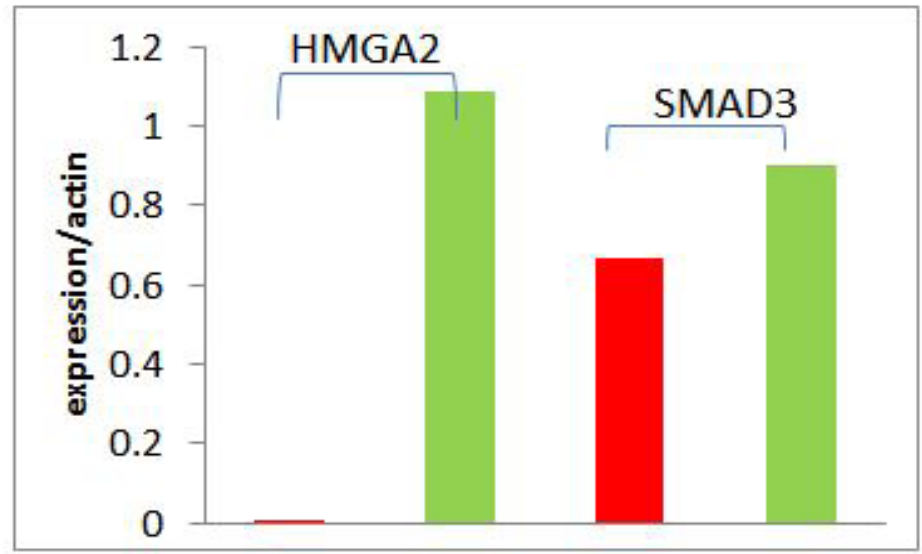

C

\section{OV2008 C13}

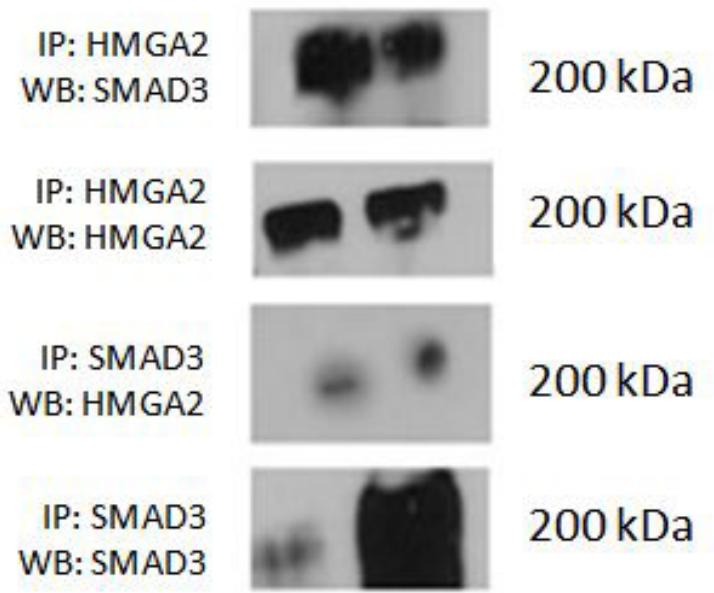

Figure 4: HMGA2/SMAD3 form a large protein complex in OC cells. A) Cell lysates from the drug-sensitive OV2008 and the drug-resistant C13 OC cells were subjected to Western immunoblotting for HMGA2 (upper panel). The blots were then stripped and re-probed for SMAD3 (middle panel) and actin (lower panel). Western blot of these cell lysates with HMGA2 and SMAD3 antibodies produced identical high MW products at 100 and $200 \mathrm{kDa}$. B) Graph depicts the densitometry analyses of the HMGA2 and SMAD3 $200 \mathrm{kDa}$ protein bands shown in (A) as expression protein profiles normalized to actin for OV 2008 (red bars) and C13 (green bars). C) Cell lysates from OV2008 and C13 cells were immunoprecipitated with HMGA2 antibodies and probed with anti-HMGA2 or anti-SMAD3 antibodies. Likewise, cell lysates were immunoprecipitated with SMAD3 antibodies and probed with anti-HMGA2 or anti-SMAD3 antibodies.

\section{Levels of HMGA2/SMAD3 and SNAIL1 increase with emergence of drug-resistance}

About $20 \%$ of OC tumors exhibit primary resistance to platinum compounds and the majority of women who respond to initial chemotherapy relapse with emergence of drug resistant disease [2,3]. To determine whether the HMGA2/SMAD3 complex has a clinical impact related to drug-resistance, we measured levels of HMGA2, SMAD3 and their downstream target, SNAIL1 [38,39], in a temporal manner during selection of drug resistance in cell culture. The drug sensitive OC cell line, OV90, was sequentially 
treated over 4 months with biweekly treatments of $4 \mathrm{x} 5 \mu \mathrm{M} \mathrm{CB}$ followed by biweekly treatments of $4 \mathrm{x} 10 \mu \mathrm{M}$ CB. Selection for drug-resistance was accompanied with a 70\% increase in cell growth (Figure 5A) compared with the parental cell line. When challenged with a single dose of $25 \mu \mathrm{M} \mathrm{CB}$, the parental cells remained responsive to CB-induced cytotoxicity and demonstrated a $35 \%$ reduction in cell viability. In contrast, when challenged with a single dose of $25 \mu \mathrm{M} \mathrm{CB}$, cells selected for drug resistance demonstrated only $23 \%$ reduction in cell viability compared to their respective untreated controls. Further, cells selected for drug resistance and treated with a single dose of $25 \mu \mathrm{M}$ CB demonstrated overall growth more than twice that of parental cells similarly treated with a single dose of $25 \mu \mathrm{M}$ CB. Enhanced genotoxic survival and cell proliferation appeared related to HMGA2/SMAD3 complex formation (Figure 5B, C) in which increased levels of $200 \mathrm{kDa}$ SMAD3 preceded overexpression of $200 \mathrm{kDa}$ HMGA2. This is in keeping with previous reports that SMAD3 and SMDA4 are crucial for induction of HMGA2 transcription [38]. In addition, increased HMGA2 and SMAD3 protein expression was related to enhanced SNAIL1 expression (Figure 5D). Consequently, increased production of an HMGA2/SMAD3 complex may be related to drug resistance and cancer progression since enhanced expression of SNAIL1 has been reported to promote emergence of drug-resistant disease and increased cancer cell proliferation by maintaining an EMT phenotype [45].

A

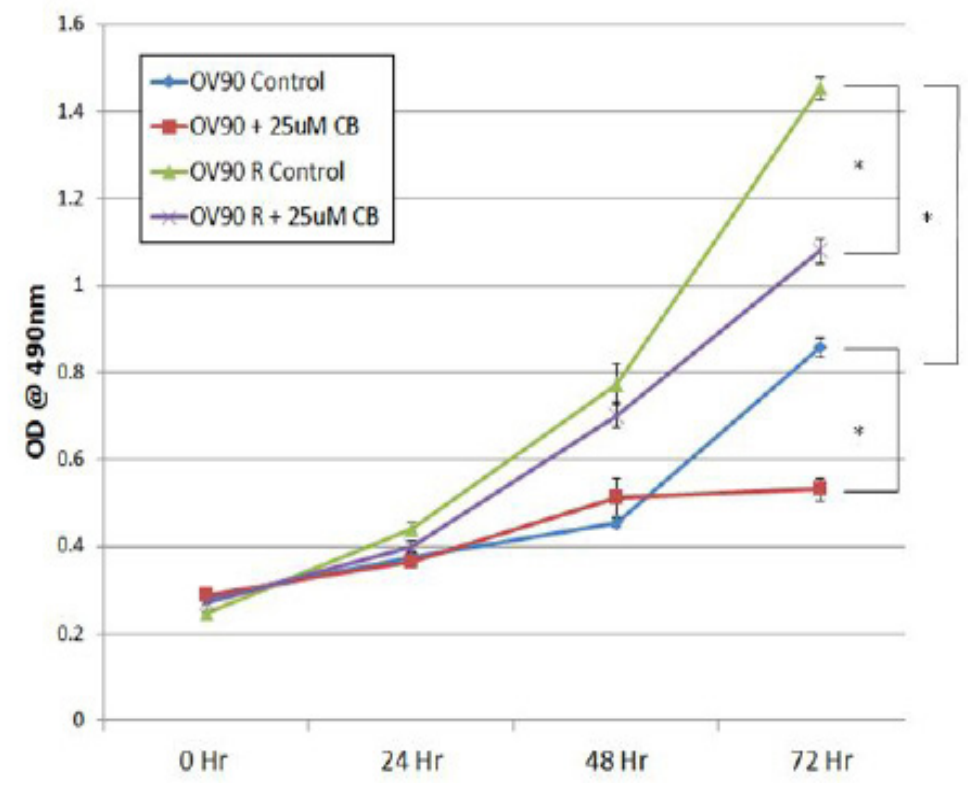

B

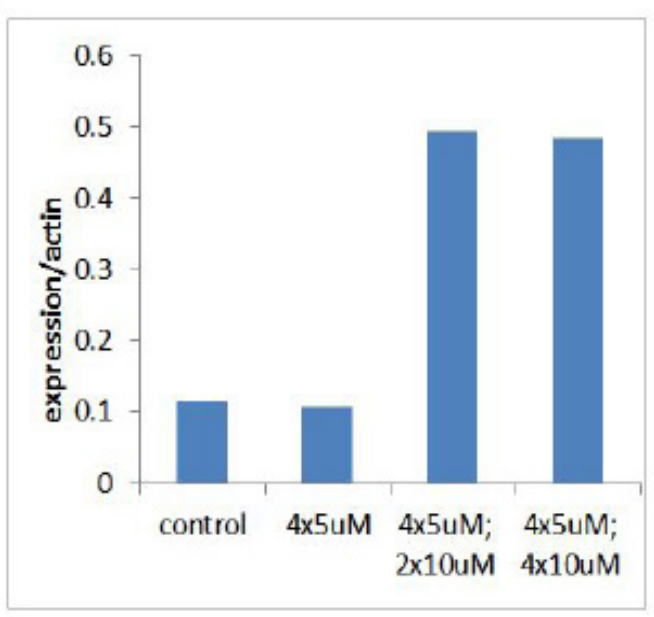

C

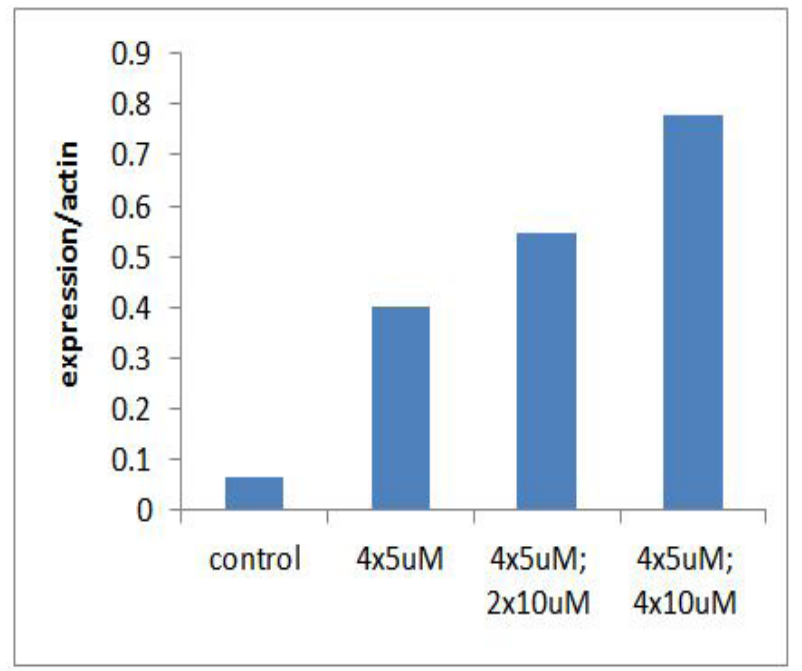

$\mathrm{D}$

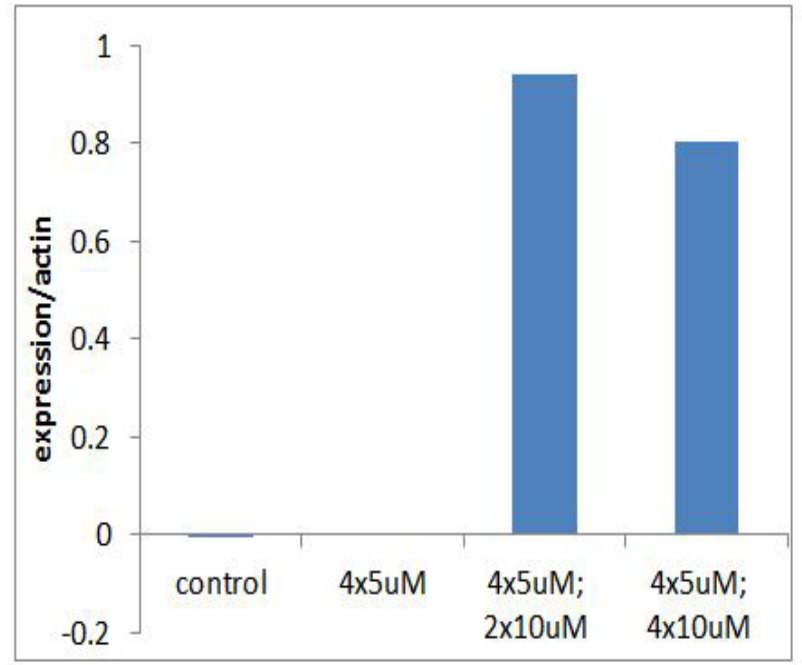

Figure 5: Levels of HMGA2, SMAD3 and SNAIL1 increase following selection for drug resistance in OC cells. A) MTS assay was performed in OV90 drug-sensitive parental cells with (red) and without (blue) a single challenge of $25 \mu \mathrm{M} \mathrm{CB}$. MTS was also performed in OV90 cells selected (OV90 R) with prior 4x5uM; 4x10 uM CB and then with (purple) and without (green) a single challenge of $25 \mu \mathrm{M} \mathrm{CB}$. Results are the average of triplicate samples \pm S.E. ${ }^{*} \leq 0.001$. Parallel cell lysates were collected from OV90 OC cells at the indicated intervals following CB selection and subjected to WB for $200 \mathrm{kDa}$ HMGA2 (B), $200 \mathrm{kDa}$ SMAD3 (C) and $29 \mathrm{kDa}$ SNAIL1 (D). Blots were analyzed by densitometry and the results expressed as the relative amount of target protein normalized to actin. 


\section{OC cells secrete HMGA2/SMAD3}

To date, studies have focused on the cytoplasmic to nuclear translocation and transcriptional activities of HMGA2/SMAD3 without regard to possible extra-nuclear functions of HMGA2/SMAD3. However, Winter et al. demonstrated HMGA2 protein bound to cell-free DNA in amniotic fluid deemed secreted by amniotic fluid cells [46], suggesting the possibility of extracellular HMGA2 localization. Given that our computational data suggested that HMGA2 could be recruited to the cell membrane by SMAD3, we sought to determine whether HMGA2 and HMGA2 complexes could be found extracellularly in OC. Conditioned media (CM) from OV2008 and C13 cells were analyzed by WB for expression of large molecular weight (200 kDa) HMGA2/SMA3 bands. We not only found $200 \mathrm{kDa}$ HMGA2/SMAD3 in the CM suggesting that HMGA2/SMAD3 complex can be secreted by OC cells, but noted that there were $88 \%$ and $10 \%$ greater levels of $200 \mathrm{kDa}$ HMGA2 and SMAD3, respectively, in the CM of C13 cells compared to OV2008 cells (Figure 6A).

For clinical validation, we measured HMGA2 and SMAD3 protein levels by WB in urinary samples obtained from healthy controls and women with gynecological disorders. In order to obtain sufficient amounts of protein for WD, initial studies comparing urinary levels of $18 \mathrm{kDa}$ HMGA2 among healthy controls and women with OC necessitated pooling urine samples. In comparison to a positive control consisting of a C13 OC cell lysate, negligible levels of HMGA2 were found in the urine of healthy donors (Figure 6B). However, among 2 pooled urinary samples (representing a total of 10 patients), HMGA2 protein levels were 10 fold greater than healthy controls. Likewise, greater levels of high MW (200 kDa) HMGA2/SMAD3 proteins were found in the urine of OC patients (>1000 times) compared to urine from women with benign disease (Figure 6C).

Given the relationship between levels of the HMGA2/SMAD3 complex with OC progression, further studies of urinary levels of HMGA2/SMAD3 alone or in combination with other urinary biomarkers [47-49] are warranted. These may offer a non-invasive, convenient and cost-effective prognostic tool for this lethal gynecologic malignancy. This may be especially relevant when assessing co-morbidity factors associated with OC. For example, a recent study by Califano et al. demonstrated a link between high body mass index (BMI) and overexpression of HMGA2 in OC tissues with poor clinical outcome and poor response to chemotherapy [50]. Importantly, since the HMGA2/SMAD3 complex is secreted by OC cells and is present in urine, changes in the levels or components of the circulating HMGA2/SMAD3 complex may have clinical impact. Lastly, by beginning to understand the components and mechanisms of an HMGA2/SMAD3 complex that drives SNAIL1-mediated drug resistance in OC, it may be possible to abrogate complex formation for therapeutic intervention.

A

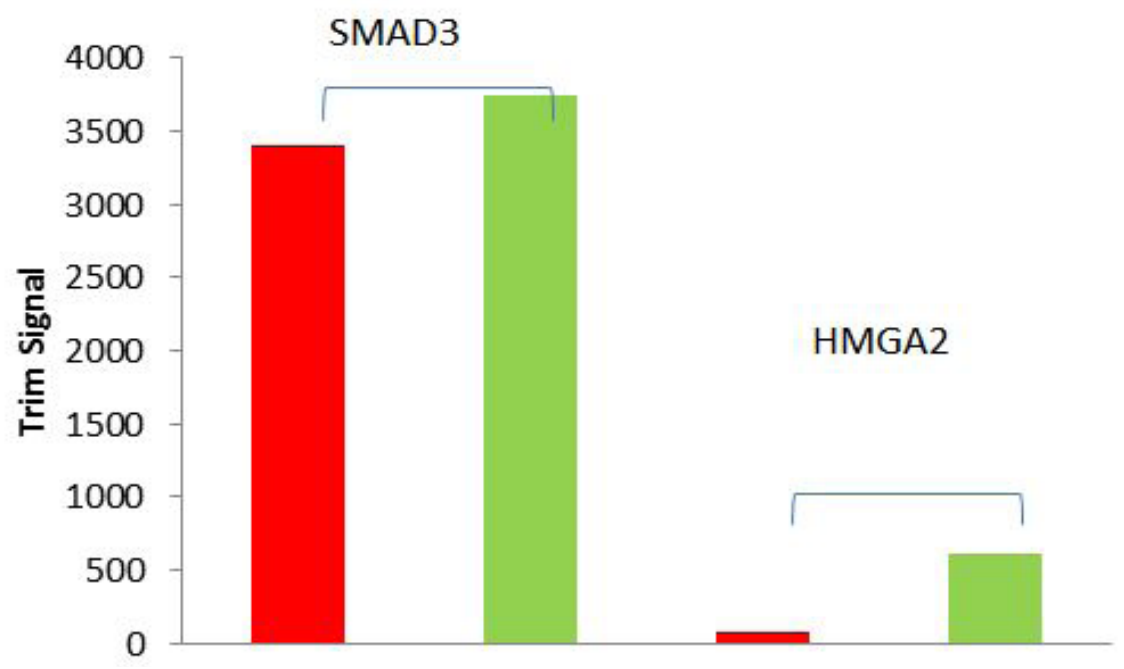

B

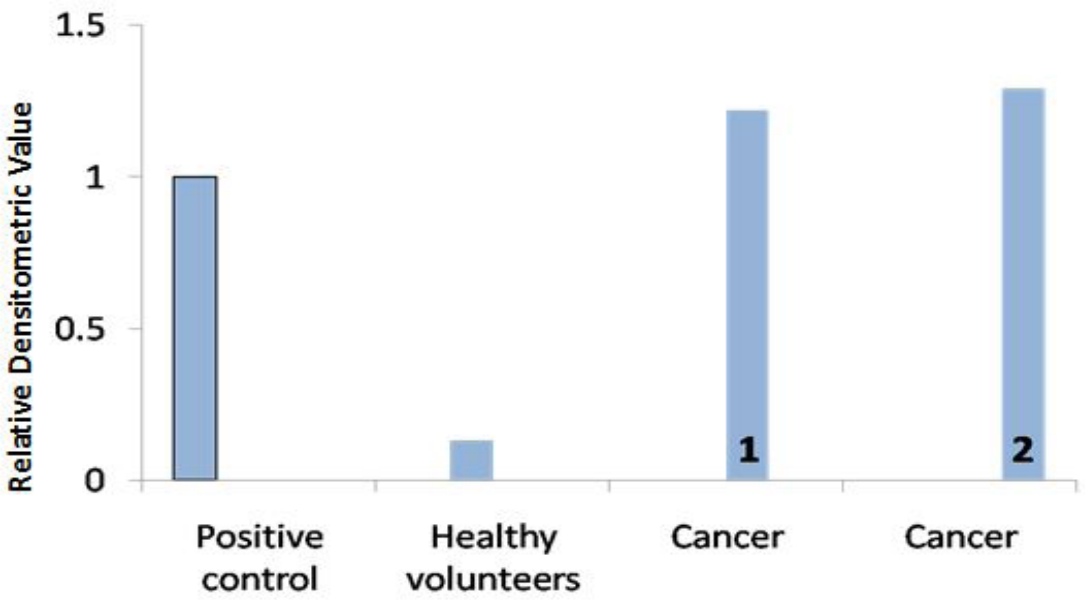


C

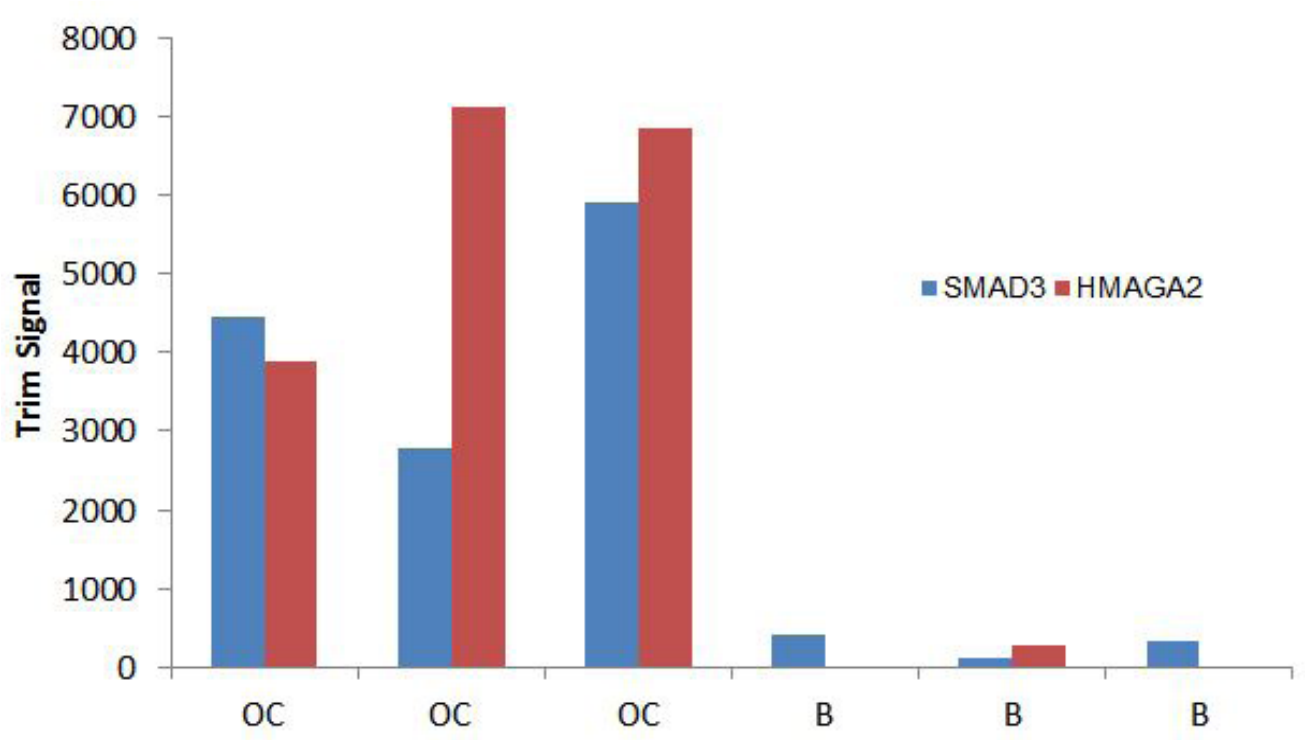

Figure 6: OC progression is associated with increased levels of extracellular HMGA2/SMAD3. A) Western immunoblots were performed on $30 \mu \mathrm{g}$ OV2008 (red) and C13 (green) conditioned media protein. Blots were probed with antibodies to HMGA2 or SMAD3 and analyzed for expression of $200 \mathrm{kDa}$ bands. B) Urinary levels of HGMA2 $(18 \mathrm{kDa})$ in healthy women and in patients were probed with antibodies to HMGA2 and analyzed for expression of HMGA2 at $18 \mathrm{kDa}$. C13 OC cell lysate served as positive control with relative density value set at ' 1 ' and urinary samples normalized to this cell lysate. The normal urine is a pool of 5 samples while cancer groups 1-2 each represent a pool of 5 urinary samples. C) Urine from women with benign gynecologic disease (B) or OC were subjected to Western immunoblotting for expression of HMGA2 (red bars) and SMAD3 (blue bars) at $200 \mathrm{kDa}$. All blots were analyzed by densitometry and the results expressed as the relative amount of target protein normalized to actin.

\section{Conclusion}

Taken together, the identification of an HMGA2/SMAD3 complex in OC may provide a new target for clinical management as urinary levels of such a complex may be of diagnostic and prognostic relevance in this gynecologic malignancy. Interference with the HMGA2/SMAD3 complex itself, then, may be therapeutically advantageous.

\section{Acknowledgment}

This work was supported, in part, by a Program Project Developmental Grant (PDD/USF/01.2011) from the Ovarian Cancer Research Fund to SVN and PAK.

\section{References}

1. Siegel RL, Miller KD, Jemal A (2015) Cancer Statistics, 2015. CA Cancer J Clin 65: 5-29.

2. Colombo PE, Fabbro M, Theillet C, Bibeau F, Rouanet P, et al. (2014) Sensitivity and resistance to treatment in the primary management of epithelial ovarian cancer. Crit Rev Oncol Hematol 89: 207-16.

3. Markman M, Bookman MA (2000) Second-line treatment of ovarian cancer. Oncologist 5: 26-35.

4. Cattaruzzi G, Altamura S, Tessari MA, Rustighi A, Giancotti V, et al. (2007) The second AT-hook of the architectural transcription factor HMGA2 is determinant for nuclear localization and function. Nuc Acids Res 35: 1751-60.

5. Rogalla P, Drechsler K, Kazmierczak B, Rippe V, Bonk U, et al. (1997) Expression of HMGI-C, a member of the high mobility group protein family, in a subset of breast cancers: relationship to histologic grade. Mol Carcinog 19: 153-6.

6. Meyer B, Loeschke S, Schultze A, Weigel T, Sandkamp M, et al. (2007) HMGA2 overexpression in non-small cell lung cancer. Mol Carcinog 46: 503-11.

7. Abe N, Watanabe T, Suzuki Y, Matsumoto N, Masaki T, et al. (2003) An increased high-mobility group A2 expression level is associated with malignant phenotype in pancreatic exocrine tissue. Br J Can 89: 2104-9.

8. Jin L, Lloyd RV, Henry MR, Erickson LA, Sebo TJ, et al. (2015) The diagnostic utility of combination of HMGA2 and IMP3 qRT-PCR testing in thyroid neoplasms. Appl Immunohistochem Mol Morphol 23: 36-43.

9. Liu B, Pang B, Hou X, Fan H, Liang N, et al. (2014) Expression of high-mobility group AT-hook protein 2 and its prognostic significance in malignant gliomas. Hum Pathol 45: 1752-8.

10. Hetland TE, Holth A, Kaern J, Florenes VA, Trope CG, et al. (2012) HMGA2 protein expression in ovarian serous carcinoma effusions, primary tumors, and solid metastases. Virchows Arch 460: 505-13.

11. Wu J, Wei JJ (2013) HMGA2 and high-grade serous ovarian carcinoma. J Mol Med 91: 1155-65.

12. Wei JJ, Wu J, Luan C, Yeldandi A, Lee P, et al. (2010) HMGA2: a potential biomarker complement to P53 for detection of early-stage high-grade papillary serous carcinoma in fallopian tubes. Am J Surg Pathol 34: 18-26.

13. Dobrinski K, Esposito NN, Kruk PA, Wenham R, Hoffman M, et al. (2014) Procurement and cytological features of human fallopian tube fimbrial cells by ex vivo imprinting and washing. J Am Soc Cytopathol 3: 309-18.

14. Roh MH, Yassin Y, Miron A, Mehra KK, Mehrad M, et al. (2010) High-grade fimbrial-ovarian carcinomas are unified by altered p53, PTEN and PAX2 expression. Mod Pathol 23: 1316-24. 
15. Sun M, Song CX, Huang H, Frankenberger CA, Sankarasharma D, et al. (2013) HMGA2/TET1/HOXA9 signaling pathway regulates breast cancer growth and metastasis. Proc Natl Acad Sci USA 110: 9920-5.

16. Morishita A, Zaidi MR, Mitoro A, Sankarasharma D, Szabolcs M, et al. (2013) HMGA2 is a driver of tumor metastasis. Can Res 73: 4289-99.

17. Xia YY, Yin L, Tian H, Guo WJ, Jiang N, et al. (2015) HMGA2 is associated with epithelial-mesenchymal transition and can predict poor prognosis in nasopharyngeal carcinoma. Oncol Targets Ther 8: 169-76.

18. Lee CT, Wu TT, Lohse CM, Zhang L (2014) High-mobility group AT-hook 2: an independent marker of poor prognosis in intrahepatic cholangiocarcinoma. Hum Pathol 45: 2334-40.

19. Dangi-Garmella S, Kranta SB, Barron MR, Shields MA, Heiferman MJ, et al. (2011) Three-dimensional collagen 1 promotes gemcitabine resistance in pancreatic cancer through MTI-MMP-mediated expression of HMGA2. Can Res 71: 1019-28.

20. Wu J, Liu Z, Shao C, Gong Q, Hernando E, et al. (2011) HMGA2 overexpression-induced ovarian surface epithelial transformation is mediated through regulation of EMT genes. Can Res 71: 349-59.

21. Summer H, Li O, Bao Q, Zhan L, Peter S, et al. (2009) HMGA2 exhibits dRP/AR site cleavage activity and protects cancer cells from DNA-damage-induced cytotoxicity during chemotherapy. Nuc Acids Res 37: 4371-84.

22. Helland A, Anglesio MS, George J, Cowin PA, Johnstone CN, et al. (2011) Deregulation of MYCN, LIN28B and LET7 in a molecular subtype of aggressive highgrade serous ovarian cancers. PloS One 6: e18064.

23. Liu Q, Liu T, Zheng S, Gao X, Lu M, et al. (2014) HMGA2 is down-regulated by microRNA let-7 and associated with epithelial-mesenchymal transition in oesophageal squamous cell carcinomas of Kazakhs. Histopathol 65: 408-17.

24. Malek A, Bakhidze E, Noske A, Sers C, Aigner A, et al. (2008) HMGA2 gene is a promising target for ovarian cancer silencing therapy. Int J Cancer 123: 348-56.

25. Romero P, Obradovic Z, Li X, Garner EC, Brown CJ, et al. (2001) Sequence complexity of disordered protein. Proteins 42: 38-48.

26. Obradovic Z, Peng K, Vucetic S, Radivojac P, Brown CJ, et al. (2003) Predicting intrinsic disorder from amino acid sequence. Proteins 53: 566-72.

27. Peng K, Radivojac P, Vucetic S, Dunker AK, Obradovic Z (2006) Length-dependent prediction of protein intrinsic disorder. BMC Bioinformat 7: 208.

28. Xue B, Dunbrack RL, Williams RW, Dunker AK, Uversky VN (2010) PONDR-FIT: a meta-predictor of intrinsically disordered amino acids. Biochim Biophys Acta 1804: 996-1010.

29. Garbuzynskiy SO, Lobanov MY, Galzitskaya OV (2010) FoldAmyloid: a method of prediction of amyloidogenic regions from protein sequence. Bioinformat 26: $326-32$.

30. Dosztanyi Z, Meszaros B, Simon I (2009) ANCHOR: web server for predicting protein binding regions in disordered proteins. Bioinformat 25: 2745-6.

31. Dosztanyi Z, Csizmok V, Tompa P, Simon I (2005) IUPred: web server for the prediction of intrinsically unstructured regions of proteins based on estimated energy content. Bioinformat 21: 3433-4.

32. Szklarczyk D, Franceschini A, Kuhn M, Simonovic M, Roth A, et al. (2001) The STRING database in 2011: functional interaction networks of proteins, globally integrated and scored. Nuc Acid Res 39: D561-8.

33. Tsaousis GN, Bagos PG, Homodrakas SJ (2014) HMMpTM: improving transmembrane protein topology prediction using phosphorylation and glycosylation site prediction. Biochim Biophys Acta 1844: 316-22.

34. Maines-Bandiera SL, Kruk PA, Auersperg N (1992) Simian virus 40-transformed human ovarian surface epithelial cells escape normal growth controls but retain morphogenetic responses to extracellular matrix. Am J Obstet Gynecol 167: 729-35.

35. Uversky VN (2011) Multitude of binding modes attainable by intrinsically disordered proteins: a portrait gallery of disorder-based complexes. Chem Soc Rev 40: $1623-34$

36. Sgarra R, Rustighi A, Tessari MA, Bernardo JD, Altamura S, et al. (2004) Nuclear phosphorproteins HMGA and their relationship with chromatin structure and cancer. FEBS Lett 574: 1-8.

37. Li H, Xu D, Toh BH, Liu JP (2006) TGB-beta and cancer: is Smad2 a repressor of hTERT gene. Cell Res 16: 169-73.

38. Thuault S, Tan EJ, Peinado H, Cano A, Heldin CH, et al. (2008) HMGA2 and Smads co-regulate SNAIL1 expression during induction of epithelial-tomesenchymal transition. J Biol Chem 283: 33437-46.

39. Thuault S, Valcourt U, Petersen M, Manfioletti G, Heldin CH, et al. (2006) Transforming growth factor-beta employs HMGA2 to elicit epithelial-mesenchymal transition. J Cell Biol 174: 175-83.

40. Makkar P, Metpally RPR, Sangadala S, Reddy BV (2009) Modeling and analysis of MH1 domain of Smads and their interaction with promoter DNA sequence motif. J Mol Graphics Model 27: 803-12.

41. Hock R, Witte F, Brocher J, Schutz M, Scheer U (2006) Expression of HMGA2 variants during oogenesis and early embryogenesis. Eur J Cell Biol 85: 519-28.

42. Rizzi C, Cataldi P, Iop A, Isola M, Sgarra R, et al. (2013) The expression of the high-mobility group A2 protein in colorectal cancer and surrounding fibroblasts is linked to tumor invasiveness. Hum Pathol 44: 122-32.

43. Zong Y, Huang J, Sankarasharma D, Morikawa T, Fukayama M, et al. (2012) Stromal epigenetic dysregulation is sufficient to initiate mouse prostate cancer via paracrine Wnt signaling. Proc Natl Acad Sci USA 109: E3395-404.

44. Popelka H, Uversky VN, Klionsky DJ (2014) Identification of Atg3 as an intrinsically disordered polypeptide yields insights into the molecular dynamics of autophagy-related proteins in yeast. Autophagy 10: 1093-104.

45. Haslehurst AM, Koti M, Dharsee M, Nuin P, Evans K, et al. (2012) EMT transcription factors snail and slug directly contribute to cisplatin resistance in ovarian cancer. BMC Cancer 12: 91.

46. Winter N, Neumann A, Bullerdiek J (2008) Cell-free DNA in amniotic fluid remains to be attached to HMGA2 - implications for noninvasive prenatal diagnosis. Prenat Diagn 28: 1126-30.

47. Drenberg CD, Saunders BO, Wilbanks GD, Chen R, Nicosia RF, et al. (2010) Urinary angiostatin levels are elevated in patients with epithelial ovarian cancer. Gynecol Oncol 117: 117-24.

48. Anderson NC, Bermudez Y, Badgwell D, Chen R, Nicosia SV, et al. (2009) Urinary levels of Bcl-2 are elevated in ovarian cancer patients. Gynecol Oncol 112: $60-7$.

49. Badgwell D, Lu Z, Cole L, Fritsche H, Atkinson EN, et al. (2007) Urinary mesothelin provides greater sensitivity for early stage ovarian cancer than serum mesothelin, urinary hCG free beta subunit and urinary hCG beta core fragment. Gynecol Oncol 106: 490-7.

50. Califano D, Pignata S, Losito NS, Ottaiano A, Greggi S, et al. (2014) High HMGA2 expression and high body mass index negatively affect the prognosis of patients with ovarian cancer. J Cell Physiol 229: 53-9. 


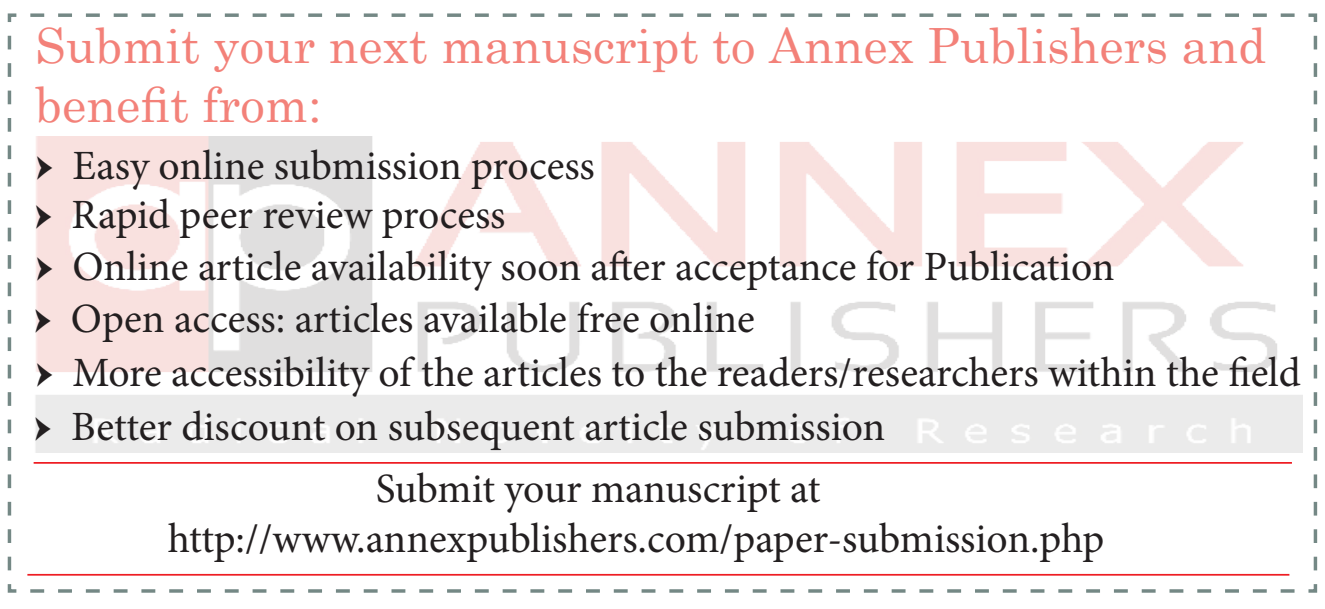

